Thus the effectiveness of the alpha-2 adrenoceptor agonists fails to prove the hypothesis than clozapine-induced hypersalivation is due to alpha-2 adrenoceptor blockade.

Furthermore, there is evidence indicating that it is unlikely that the hypersalivation caused by clozapine is mediated by alpha- 2 adrenoceptors. Firstly, the antidepressant drug mianserin which has a higher affinity for alpha-2 adrenoceptors that clozapine, not only fails to cause hypersalivation, but in fact it causes a significant (60\% after a single dose of $20 \mathrm{mg}$ ) reduction in salivary output (Ogura et al, 1987). This effect of mianserin cannot be due to muscarinic receptor blockade since mianserin has a much lower affinity of muscarinic receptors than clozapine. Secondly, the atypical antipsychotic drug remoxipride also causes hypersalivation as a sideeffect, however, it is a highly selective dopamine $\mathrm{D}_{2}$ receptor antagonist with extremely low affinities for other neurotransmitter receptors, including the alpha-2 adrenoceptor.

Thus, the way in which clozapine causes hypersalivation remains an enigma.

Corrigan, F. M., MacDonald, S. \& Reynolds, G. P. (1995) Clozapine-induced hypersalivation and the alpha-2 adrenoceptor. (Letter.) British Journal of Psychiatry, 167, 412.

Fritze, J. \& Eulnger, T. (1995) Pirenzepine for clozapineinduced hypersalivation. Lancet, 346, 1034.

GrabowsKI, J. (1992) Clonidine treatment of clozapine-induced hypersalivation. Journal of Clinical Psychopharmacology, 12, 69-70.

Ogura, C., Kishmoto, A., Mizukawa, R., et al (1987) Comparative study of the effects of 9 antidepressants on several physiological parameters in healthy volunteers. Neuropsychobiology, 17, 139-144.

Richelson, E. \& Neison, A. (1984) Antagonism by neuroleptics of neurotransmitter receptors of normal human brain in vitro. European Journal of Pharmacology, 103, 197-204.

E. SZABADI

Department of Psychiatry

University of Nottingham

Nottingham NG7 2 UH

\section{Influences on cost effectiveness}

SIR: Hotopf et als (1996) review of randomised controlled trials comparing the cost-effectiveness of SSRIs $v$. tricyclic antidepressants concluded that although SSRIs appeared to be safer and better tolerated, these advantages did not justify their extra costs. However, their review has not considered the fact that the cost of drugs is strongly influenced by regional economic factors such as the differing interpretations of drug patent rules, the production of generic drugs and the variable dose strengths of pharmaceutical preparations. To make this point clearer, I will elaborate from drug experience in India (using figures from Drug Today, January-March 1996). Altogether, there are 16 preparations of fluoxetine available with prices for 10 capsules of $20 \mathrm{mg}$ strength ranging from 12 to 48 Rupees. If one excludes the single preparation costing $48 \mathrm{Rs}$, the mean cost for 10 capsules is around $20 \mathrm{Rs}$. Of note, none of the preparations are 'compound' i.e. combined with other psychotropic drugs. Two commonly used tricyclics in India are imipramine and amitryptiline. Both are commonly available in $25 \mathrm{mg}$ and $75 \mathrm{mg}$ dosage strengths; many preparations are compound with combinations usually being diazepam and chlordiazepoxide. For the sake of comparison, I only include pure pharmacological preparations of imipramine or amitryptiline. Taking the former, the mean cost of $75 \mathrm{mg}$ preparations (strip of 10) is $13.9 \mathrm{Rs}$ and for $25 \mathrm{mg}$ preparations (strip of 10) is $5.1 \mathrm{Rs}$; equivalent prices for amitryptiline are $15.7 \mathrm{Rs}$ and $7 \mathrm{Rs}$. Of note, the minimum price of $75 \mathrm{mg}$ preparations for both tricyclics is 11 Rs.

It is important that any discussion on the costeffectiveness of interventions (whether pharmacological or psychological) should stress that they are as much influenced by regional political and economic factors as by clinical outcome indicators.

Hotopf, M., LewIS, G. \& Normand, C. (1996) Are SSRIs a cost-effective alternative to tricyclics? British Journal of Psychiatry, 168, 404-409.

Institute of Psychiatry \& Human Behaviour V. PATEL

Altinho, Panjum

Goa 403001, India

\section{Cytochromes and psychotropic drug interactions}

SIR: Taylor \& Lader (1996) have provided a timely editorial on the cytochrome P-450 enzyme system and the practical implications of its role in the metabolism of psychotropic drugs. It should not be overlooked, however, that the cytochrome P-450 enzyme system is also involved in the metabolism of commonly prescribed non-psychotropic drugs such as beta-blockers, type 1C antiarrhythmics and morphine derivatives, and knowledge of their pharmacokinetics is essential to avert adverse cytochrome-mediated drug interactions.

Although the authors rightly recommend the use of alternative drugs which interact to a lesser degree with the cytochrome $\mathrm{P}-\mathbf{4 5 0}$ system, they state 
that the use of ketoconazole is 'rarely necessary'. Fluconazole is a good substitute for ketoconazole as an antifungal agent but at higher concentrations ketoconazole also has widespread inhibitory effects on the cytochrome P-450 enzymes involved in adrenocortical steroidogenesis (Raven \& Hinson, 1996). As these include 17 $\alpha$-hydroxylase and $11 \beta$ hydroxylase but not 21-hydroxylase, there is no consequent increase in ACTH and resulting 'cortisol escape'. For this reason, ketoconazole is recommended as the drug of choice to decrease excess cortisol production (American Medical Association, 1993). Because of its cortisol-lowering effect, ketoconazole has also been advocated as a treatment for major depression, a disorder associated with hypercortisolaemia.

American Medical Association (1993) Drug Evaluations Annual Chicago: American Medical Association.

Raven, P. W. \& Hinson, J. P. (1996) Transport, actions and metabolism of adrenal hormones and pathology and pharmacology of the adrenal gland. In The Adrenal in Toxicology (ed. P. W. Harvey), pp. 53-79. London: Taylor \& Francis.

P.A. COTTER P.W. RAVEN

Institute of Psychiatry

London SE5 8AF

\section{Consent to treatment}

SIR: We read with interest the recent article by Brabbins et al (1996) in which the authors make a strong argument for clinicians seeking informed consent for neuroleptic treatment in the majority of schizophrenic patients. They conclude that a pro forma could be used to record patient consent which would include a record of information given, benefits and risks discussed, measurement of capacity to consent and the absence of duress.

While agreeing with the argument for pursuing informed consent in this patient group, it is not so clear to us that the use of a formalised pro forma is the best method of recording consent. A recent American Psychiatric Association task force report (1992) recommended that informed consent for neuroleptic treatment should be documented by a progress note rather than by use of consent forms. This was felt to reflect an understanding of informed consent as a process rather than an event. Such thinking is consistent with recommended UK practice, i.e. that 'consent' is the voluntary and continuing permission of the patient to receive a particular treatment (Department of Health, 1993). In a recent survey of 81 British consultant psychiatrists we asked whether they would consider using a standardised consent form for patients on long-term neuroleptic treatment. Only $31 \%$ responded positively despite $73 \%$ admitting to concerns in regard to future litigation from patients going on to develop tardive dyskinesia. There is clearly some resistance among British clinicians to the use of formalised consent forms. The obtaining of informed consent for treatment is an ongoing process and should be recorded in such a manner that reflects this process. A single pro forma, however detailed, may therefore be counter-productive.

Brabbins, C., Butler, J. \& Bentall, R. (1996) Consent to neuroleptic medication for schizophrenia: clinical, ethical and legal issues. British Journal of Psychiatry, 168, 540-544.

Department of Health (1993) Code of Practice of the Mental Health Act 1983.

American Psychiatric Assoclation (1992) Tardive Dyskinesia: A Task Force Report of the American Psychiatric Association. Washington, D.C: APA.

J. LAUGHARNE

J. ARCELSUS

University Department of Psychiatry

A. DAVIES

Northern General Hospital

Sheffield S5 $7 A U$

SIR: There are many issues involved in the prescribing of medication to those who may be unable to give consent. Some of these have been reviewed recently in the context of schizophrenia (Brabbins et al, 1996). However the problems arising with drug use in patients with dementia have been less well aired. Brabbins et al suggest that clinicians should document attempts to obtain informed consent, but do not answer the question, 'what should we do if this cannot be given?'. In those patients who have psychotic disorders the argument revolves around whether or not to invoke Mental Health legislation. Where patients have severe cognitive impairment informed consent is usually impossible to obtain. Current practice is to give medication without consideration of the legal status of the patient; it is administered unless the patient actively refuses to take it. Yet, there is doubt as to the efficacy of these drugs in managing behaviour related to dementia (Schneider et al, 1990). We feel quite comfortable prescribing drugs which have a definite benefit to such patients e.g. diuretics, antibiotics and cardiac drugs. However, should the use of drugs which frequently benefit the carers or other patients rather than the recipient themselves and have a high incidence of often irreversible side-effects continue in those who are 